\title{
O SIGNIFICADO E ALCANCE DA EXPRESSÃO "PRECEITO FUNDAMENTAL", NO ÂMBITO DA ARGÜIÇÃO DE DESCUMPRIMENTO DE PRECEITO FUNDAMENTAL ${ }^{1}$
}

Alberto de Magalhães Franco Filho

\begin{abstract}
RESUMO: A Argüição de Descumprimento de Preceito Fundamental é uma das espécies de fiscalização abstrata de constitucionalidade prevista no artigo 102, $\S 1^{\circ}$ da Constituição Federal de 1988, que somente ingressou em nosso ordenamento jurídico constitucional através da Emenda Constitucional n. 03/93, tendo sido regulamentada pela Lei n. 9.882/99. O seu objeto é mais amplo e complexo que as demais ações de controle abstrato de constitucionalidade, já que este instituto serve para evitar ou reparar lesão a preceito fundamental resultante de ato do poder público e ainda quando houver relevante fundamento de controvérsia constitucional sobre lei ou ato normativo federal, estadual ou municipal, incluídos os anteriores à constituição. Ocorre que o ordenamento normativo não trouxe consigo o alcance nem tampouco a significação da expressão "preceito fundamental", deixando para a doutrina e a jurisprudência tal tarefa que nos propomos a tentar sintetizar.
\end{abstract}

PALAVRAS-CHAVE: Controle Abstrato de Constitucionalidade - Preceito Fundamental - Argüição de descumprimento de Preceito Fundamental.

\section{THE MEANING AND REACH THE EXPRESSION "BASIC RULE", IN THE SCOPE OF THE CHALLENGE OF DISGEGARD OF BASIC RULE}

\begin{abstract}
The Challenge of Disregard of Basic Rule is one of the species of abstract fiscalization of constitutionality foreseen in article $102, \S 1^{\circ}$ of the Federal Constitution of 1988 , that it only entered our constitutional legal system through Constitutional Emendation n. 03/93, having been regulated for Law $\mathrm{n}$. 9.882/99. Its object is ampler and complex that the too much actions of abstract control of constitutionality, since this institute serves to prevent or to still repair injury the resultant basic rule of act of the public power and when it will have excellent bedding of constitutional controversy on law or federal normative act, state or municipal, enclosed the previous ones to the constitution. It occurs that the normative order did not bring obtains the reach neither nor the meaning of the expression "basic rule", leaving for the doctrine and the jurisprudence such task that in we consider them to try to synthecize.

KEY-WORDS: Abstract control of Constitutionality - Basic Rule - Challenge of Disregard of Basic Rule.
\end{abstract}

\section{INTRODUÇÃO}

\footnotetext{
${ }^{1}$ Artigo científico elaborado a partir de seminário apresentado pelo autor para a conclusão de créditos da disciplina: "Jurisdição Constitucional", do mestrado em Direito Coletivo e Função Social do Direito da Universidade de Ribeirão Preto -UNAERP.

2 Graduado em Direito pelo Centro Universitário de Patos de Minas - UNIPAM, Pós-graduado em Direito do Trabalho e Processo do Trabalho pelo Centro Universitário de Patos de Minas - UNIPAM, Mestrando em Direito Coletivo e Função Social do Direito ela Universidade de Ribeirão Preto UNAERP, Bolsista da CAPES pelo programa PROSUP, Professor Substituto do Centro Universitário de Patos de Minas - UNIPAM, Professor Titular da Faculdade Atenas, Advogado.
}

(C) 2008. Departamento de Direito da UFSM. Todos os direitos reservados. 
A argüição de descumprimento de preceito fundamental constitui-se o quinto instrumento de fiscalização abstrata de constitucionalidade do eclético sistema brasileiro de controle.

Para alguns ela é considerada mais uma conquista democrática, contudo a nosso ver, na verdade apenas expõe a fragilidade do nosso sistema de controle de constitucionalidade, ao passo que atenta contra à presunção de constitucionalidade que deveria revestir todos os atos jurídicos e ainda enfraquece ao principio da supremacia da Constituição.

Não obstante estas ponderações, no presente trabalho tentaremos estabelecer o alcance e a significação da expressão "prec eito fundamental", que é o objeto ou um dos objetos da argüição de descumprimento de preceito fundamental.

O presente tema é muito debatido pela doutrina que não chegou ainda a definição exata do que seria preceito fundamental, talvez em razão do alto grau de indeterminabilidade do mesmo.

\section{LOCALIZAÇÃO CONSTITUCIONAL DA ARGÜIÇÃO DE DESCUMPRIMENTO DE PRECEITO FUNDAMENTAL}

A argüição de descumprimento de preceito fundamental é um instituto recente no ordenamento jurídico nacional, instituído pela Constituição de 1988, em seu artigo 102, parágrafo único, e posteriormente regulamentado, já como $\S 1^{\circ}$ devido à redação da Emenda Constitucional n. 03/93, senão vejamos:

Art. 102. Compete ao Supremo Tribunal Federal, precipuamente, a guarda da Constituição, cabendo-lhe:

(...)

$\$ 1^{\circ}$. A argüição de descumprimento de preceito fundamental, decorrente desta Constituição, será apreciada pelo Supremo Tribunal Federal, na forma da lei." (original sem grifos)

Da leitura do Texto Magno percebe-se, que o Poder Constituinte Originário estabeleceu claramente que a argüição de descumprimento fundamental necessitaria de autuação legiferante infraconstitucional, para definir seu modus operandi e demais pontos de minúcia. 
Como o legislador ordinário não realizou seu trabalho de pronto, surgiu a discussão sobre a possibilidade ou não de se utilizar a argüição de descumprimento fundamental antes da edição da referida lei, e, por conseguinte qual era sua eficácia como norma constitucional.

Assim segundo a balizada doutrina de André Ramos Tavares $^{3}$ o $§ 1^{\circ}$ do Art. 102 da Constituição Federal de 1988 seria uma norma de eficácia imediata, porém regulamentável, tendo em vista que a argüição de descumprimento fundamental assume a feição de autogarantia constitucional, contudo este não é entendimento dominante da doutrina.

Os constitucionalistas Alexandre de Moraes $^{4}$ e Pedro Lenza ${ }^{5}$, entre outros autores e a jurisprudência do Supremo Tribunal Federal, firmaram entendimento de que norma prevista no o $\S 1^{\circ}$ do Art. 102 da Constituição Federal de 1988 constituía uma norma constitucional de eficácia limitada, ou seja, dependente de lei para sua apreciação.

Nesse sentido destacamos o seguinte julgado do STF:

ARGÜIÇÃO DE DESCUMPRIMENTO DE PRECEITO FUNDAMENTAL: ART. 102, § $1^{\circ}$, DA CONSTITUIÇÃO FEDERAL DE 1988 - DECRETO ESTADUAL DE INTERVENÇÃO EM MUNICÍPIO - ARTS. $4^{\circ}$ DA LEI DE INTRODUÇÃO AO CC E ART. 126 DO CPC - 1. O $\$ 1^{\circ}$ do art. 102 da Constituição Federal de 1988 é bastante claro, ao dispor: "a argüição de descumprimento de preceito fundamental, decorrente desta Constituição, será apreciada pelo Supremo Tribunal Federal, na forma da lei". 2. Vale dizer, enquanto não houver lei, estabelecendo a forma pela qual será apreciada a argüição de descumprimento de preceito fundamental, decorrente da Constituição, o STF não pode apreciá-la. 3. Até porque sua função precípua é de guarda da Constituição (art. 102, caput). E é esta que exige Lei para que sua missão seja exercida em casos como esse. Em outras palavras: trata-se de competência cujo exercício ainda depende de Lei. 4. Também não compete ao STF elaborar Lei a respeito, pois essa é missão do Poder Legislativo (arts. 48 e seguintes da CF). 5. E nem se trata aqui de Mandado de Injunção, mediante o qual se pretenda compelir o Congresso Nacional a elaborar a Lei de que trata $o \S 1^{\circ}$ do art. 102, se é que se pode sustentar o cabimento dessa espécie de ação, com base no art. $5^{\circ}$, inciso LXXI, visando a tal resultado, não estando, porém, sub judice, no feito, essa questão. 6. Não incide, no caso, o disposto no art. $4^{\circ}$ da Lei de Introdução ao Código Civil, segundo o qual "quando a lei for omissa, o Juiz decidirá o caso de acordo com a analogia, os costumes e os princípios gerais de direito, para resolver lide "inter partes". Tal norma não se

\footnotetext{
${ }^{3}$ TAVARES. Tratado da argüição de preceito fundamental. 2001, p. 86.

${ }^{4}$ MORAES. Direito constitucional. 2006, p. 697.

${ }^{5}$ LENZA. Direito constitucional. 2007, p. 154.
} 
sobrepõe à constitucional, que, para a argüição de descumprimento de preceito fundamental dela decorrente, perante o STF, exige Lei formal, não autorizando, à sua falta, a aplicação da analogia, dos costumes e dos princípios gerais de direito". 8. De resto, para se insurgir contra o Decreto estadual de intervenção no Município, tem este os meios próprios de impugnação, que, naturalmente, não podem ser sugeridos pelo STF. (STF AgRg em Petição 1.140-7 - TO - Plenário - Rel. Min. Sydney Sanches - DJU 31.05.1996)" (grifo nosso)

Portanto até que se fosse editada uma lei infraconstitucional sobre o procedimento da argüição de descumprimento de preceito fundamental, este instrumento de controle abstrato ou concentrado de constitucionalidade não poderia ser utilizado. A resposta legislativa só veio a lume em dezembro de 1999, através da Lei 9.882, que dispôs sobre o processo e julgamento da argüição de descumprimento de preceito fundamental.

A edição da referida norma legal possibilitou a instrumentalização da argüição de descumprimento de preceito fundamental, porém foi alvo de críticas e objeto da Ação Direta de Inconstitucionalidade - ADIn n. 2.231-8, ajuizada pelo Conselho Federal da Ordem dos Advogados do Brasil, perante o Supremo Tribunal Federal, que se encontra em tramite até o presente momento e tendo como ultimo andamento a conclusão ao relator Ministro Sepúlveda Pertence no dia 02/08/2004.

Desta forma podemos notar que a argüição de descumprimento de preceito fundamental esta localizada constitucionalmente no a art. 102, $\S 1^{\circ}$ da Carta Magna e foi disciplinada pela Lei n. 9.882 de 1999.

\section{O OBJETO DA ARGÜIÇÃO DE DESCUMPRIMENTO DE PRECEITO FUNDAMENTAL}

A Lei n. 9.882/99 ao estabelecer o objeto da ADPF assim estabeleceu:

Art. $1^{o}$ A argüição prevista no $\S 1^{o}$ do art. 102 da Constituição Federal será proposta perante o Supremo Tribunal Federal, e terá por objeto evitar ou reparar lesão a preceito fundamental, resultante de ato do Poder Público.

Parágrafo único. Caberá também argüição de descumprimento de preceito fundamental:

I - quando for relevante o fundamento da controvérsia constitucional sobre lei ou ato normativo federal, estadual ou municipal, incluídos os anteriores à Constituição;

II - Vetado (grifamos)

(C) 2008. Departamento de Direito da UFSM. Todos os direitos reservados. 
Cumpre esclarecer inicialmente que, o inc. II do parágrafo único do artigo $1^{\circ}$ foi vetado pelo Presidente da República, cujo texto dispunha: "em face da interpretação ou aplicação dos regimentos internos das respectivas Casas, ou regimento comum do Congresso Nacional, no processo legislativo de elaboração das normas previstas no art. 59 da Constituição Federal".

Nas razões de veto encaminhadas ao Presidente do Congresso Nacional (Mensagem 1.807, de 03.12.1999), relativamente ao dispositivo embargado, a Presidência da República assim se manifestou:

(...) Não se faculta ao Egrégio Supremo Tribunal Federal a intervenção ilimitada e genérica em questões afetas à interpretação ou aplicação dos regimentos internos das respectivas casas, ou regimento comum do Congresso Nacional' prevista no inciso II do parágrafo único do art. 1o. Tais questões constituem antes matéria interna corporis do Congresso Nacional. A intervenção autorizada ao Supremo Tribunal Federal no âmbito das normas constantes de regimentos internos do Poder Legislativo restringe-se àquelas em que se reproduzem normas constitucionais. Essa orientação restou assentada pelo Supremo Tribunal Federal no julgamento do Mandado de Segurança $n$. 22503-DF, Relator para o Acórdão Ministro Maurício Corrêa, DJ 06.06.97, p. 24872. Do mesmo modo, no julgamento do Mandado de Segurança n. 22183DF, Relator Ministro Marco Aurélio, o Supremo Tribunal Federal assentou: '3. Decisão fundada, exclusivamente, em norma regimental referente à composição da Mesa e indicação de candidaturas para seus cargos (art. $8^{\circ}$ ). 3.1 O fundamento regimental, por ser matéria interna corporis, só pode encontrar solução no âmbito do Poder Legislativo, não ficando sujeito à apreciação do Poder Judiciário. 3.2 Inexistência de fundamento constitucional (art. 58, $\S 1^{\circ}$ ), caso em que a questão poderia ser submetida ao Judiciário' (DJ 12-12-97, p. 65569). Dito isso, impõe-se o veto da referida disposição por transcender o âmbito constitucionalmente autorizado de intervenção do Supremo Tribunal Federal em matéria interna corporis do Congresso Nacional. No que toca à intervenção constitucionalmente adequada do Supremo Tribunal Federal, seria oportuno considerar a colmatação de eventual lacuna relativa a sua admissão, em se tratando da estrita fiscalização da observância das normas constitucionais relativas a processo legislativo.

Diante das razões de veto apontadas na mensagem acima transcrita verifica-se o cuidado em resguardar o postulado da separação dos poderes. Assim, questões eminentemente internas de cada poder, não podem ser apreciadas por outro poder.

Da análise supracitado diploma legal em vigor, percebe-se que o legislador ordinário estabeleceu que é cabível a argüição de descumprimento de preceito fundamental: 
I) para evitar lesão a preceito fundamental resultante de ato do poder público;

II) para reparar a lesão a preceito fundamental resultante de ato do poder público;

III) quando for relevante o fundamento da controvérsia constitucional sobre lei ou ato normativo federal, estadual ou municipal, incluídos os anteriores à constituição.

As duas primeiras hipóteses são espécies de argüição de descumprimento são consideradas autônomas e poder ser preventivas ("evitar lesão") e repressivas ("reparar lesão").

Gize-se que em ambas modalidades a argüição deve se dar quando ocorrer lesão à preceito fundamental. Sendo que, esta lesão deve ser resultante de ato do poder público, ou seja, qualquer ato administrativo com exclusão dos particulares, podendo este ato ser normativo ou não.

Sobre o tema, destacamos o posicionamento do Pretório Excelso:

(...)O objeto da argüição de descumprimento de preceito fundamental há de ser "ato do Poder Público" federal, estadual, distrital ou municipal, normativo ou não, sendo, também, cabivel a medida judicial "quando for relevante o fundamento da controvérsia sobre lei ou ato normativo federal, estadual ou municipal, incluídos os anteriores à Constituição". 7. Na espécie, a inicial aponta como descumprido, por ato do Poder Executivo municipal do Rio de Janeiro, o preceito fundamental da "separação de poderes", previsto no art. $2^{\circ}$ da Lei Magna da República de 1988. O ato do indicado Poder Executivo municipal é veto aposto a dispositivo constante de projeto de lei aprovado pela Câmara Municipal da Cidade do Rio de Janeiro, relativo ao IPTU. 8. No processo legislativo, o ato de vetar, por motivo de inconstitucionalidade ou de contrariedade ao interesse público, e a deliberação legislativa de manter ou recusar o veto, qualquer seja o motivo desse juízo, compõem procedimentos que se hão de reservar à esfera de independência dos Poderes Políticos em apreço. 9. Não é, assim, enquadrável, em princípio, o veto, devidamente fundamentado, pendente de deliberação política do Poder Legislativo - que pode, sempre, mantê-lo ou recusá-lo, - no conceito de "ato do Poder Público", para os fins do art. $1^{\circ}$, da Lei $n^{o}$ 9882/1999. Impossibilidade de intervenção antecipada do Judiciário, - eis que o projeto de lei, na parte vetada, não é lei, nem ato normativo, - poder que a ordem jurídica, na espécie, não confere ao Supremo Tribunal Federal, em via de controle concentrado. 10. Argüição de descumprimento de preceito fundamental não conhecida, porque não admissível, no caso concreto, em face da natureza do ato do Poder Público impugnado. (STF - ADPF n. 1 (QO) - RJ - Plenário - Rel. Min. Néri da Silveira - DJU 03.02.2000) (original sem grifos)

Agravo regimental adversando decisão que negou seguimento a argüição de descumprimento de preceito fundamental, uma vez que, à luz da Lei $n$.

(C) 2008. Departamento de Direito da UFSM. Todos os direitos reservados. 
9.882/99, esta deve recair sobre ato do poder público não mais suscetivel de alterações. A proposta de emenda à constituição não se insere na condição de ato do poder público pronto e acabado, porque ainda não ultimado o seu ciclo de formação. Ademais, o Supremo Tribunal Federal tem sinalizado no sentido de que a argüição de descumprimento de preceito fundamental veio a completar o sistema de controle objetivo de constitucionalidade. Assim, a impugnação de ato com tramitação ainda em aberto possui nítida feição de controle preventivo e abstrato de constitucionalidade, o qual não encontra suporte em norma constitucional-positiva. (ADPF 43-AgR, Rel. Min. Carlos Britto, julgamento em 20-11-03, DJ de 19-12-03) (grifamos).

A terceira hipótese de argüição de preceito fundamental é a chamada por equivalência ou equiparação.

Por meio desta hipótese é possível argüir o descumprimento de preceito fundamental quando houver controvérsia constitucional relevante sobre lei ou ato normativo federal, estadual e municipal, incluídos os anteriores à Constituição.

Assevera o constitucionalista Alexandre de Moraes $^{6}$ que esta hipótese de argüição por equiparação legal, extrapola o poder que foi conferido ao legislador ordinário pela Constituição federal, já que o $§ 1^{\circ}$ do art. 102 da Carta Política apenas autorizou o legislador a estabelecer a forma pela qual a o preceito fundamental será argüido no STF, não deu ensejo à ampliação das competências do STF, por este motivo entende ser esta hipótese inconstitucional.

Nesse sentido também é o magistério de Luiz Alberto David Araújo e Vidal Serrano Nunes Júnior:

A Constituição Federal, em seu art. 102\$ $1^{\circ}$, cuidou apenas de criar uma ação. Sempre que houver descumprimento de preceito fundamental, caberá a ação prevista na Lei Maior. Mas a Lei n. 9.882/99 inovou trazendo mais uma hipótese, ou seja, o controle de ato normativo municipal, estadual e federal, incluindo o anterior à Constituição, desde que relevante o fundamento da controvérsia constitucional na visão do Pretório Excelso.

Entendemos, portanto, que o parágrafo único do art. $1^{\circ}$ da Lei $n .9 .882 / 99$, por inexistência de previsão é inconstitucional, permitindo apenas o controle pela ação prevista na cabeça deste artigo ${ }^{7}$.

Registre-se também que consoante noticiado no Informativo n. 253 do Supremo Tribunal Federal, o Ministro Néri da Silveira - relator da ADIn n. 2.231/DF - afirma que

\footnotetext{
${ }^{6}$ MORAES. Direito constitucional. 2005, p. 702.

${ }^{7}$ ARAUJO; NUNES JÚNIOR. Curso de direito constitucional. 2006, p. 56.
} 
a argüição de descumprimento de preceito fundamental na modalidade incidental, somente poderia ser criada através de emenda constitucional, senão vejamos:

(...) O Min. Néri da Silveira, relator, em face da generalidade da formulação do parágrafo único do art. $1^{o}$, considerou que esse dispositivo autorizaria, além da argüição autônoma de caráter abstrato, a argüiçãa incidental em processos em curso, a qual não poderia ser criada pelo legislador ordinário, mas, tão-só, por via de emenda constitucional, e, portanto, proferiu voto no sentido de dar ao texto interpretação conforme à $C F$ a fim de excluir de sua aplicação controvérsias constitucionais concretamente já postas em juízo ('Parágrafo único - Caberá também argüição de descumprimento de preceito fundamental: I - quando for relevante o fundamento da controvérsia constitucional sobre lei ou ato normativo federal, estadual ou municipal, incluídos os anteriores à Constituição'"). Conseqüentemente, o Min. Néri também votou pelo deferimento da liminar para suspender a eficácia do $\$ 3^{\circ}$ do art. $5^{\circ}$, por estar relacionado com a argüição incidental em processos em concreto ('A liminar poderá consistir na determinação de que juízes e tribunais suspendam o andamento de processo ou os efeitos de decisões judiciais, ou de qualquer outra medida que apresente relação com a matéria objeto da argüição de descumprimento de preceito fundamental, salvo se decorrentes da coisa julgada.') (grifamos).

\section{A EXPRESSÃO "PRECEITO FUNDAMENTAL"}

Uma das grandes dificuldades que se afigura sobre o estudo do tema é exatamente a identificação e a conceituação de preceito fundamental na ordem constitucional, tendo em vista que nem a Constituição e nem a Lei n. 9.882/99 definiram o seu conceito, relegando-se esta árdua tarefa à doutrina e a jurisprudência.

Então para se atingir o conceito aludido é pertinente fragmentarmos a expressão contida no $\S 1^{\circ}$ do art. 102 da $\mathrm{CF} / 88$ : "preceito fundamental".

Passemos inicialmente à definição do que seria preceito.

Antes e mais nada é imperioso salientar que o Direito é uma unidade de sentido onde os valores são incorporados à norma, e o Direito Constitucional constitui-se de um sistema aberto de normas.

As normas, por sua vez, subdividem-se em duas espécies: os princípios e as regras. Os princípios são comandos gerais dotados de alto grau de abstração, com amplo campo de incidência e abrangência, servindo como norte para o ordenamento jurídico. Por sua vez, as regras são comandos aplicáveis em um campo de incidência específico, 
com elementos próximos ao direito comum, capazes de investir um titular em direitos subjetivos.

Segundo o magistério de De Plácido e Silva em sua obra Vocabulário Jurídico, citada por André Ramos Tavares ${ }^{8}$, a palavra preceito, derivada do latim praeceptum, significa a ordem, a regra ou o mandado que se deve observar. Portanto assume a noção de norma.

Como se vê o preceito é sem dúvida uma norma, porém não podemos afirmar que ele seria nem principio nem regra, mas sem a menor sobra de dúvida uma categoria à parte, mas sendo pois, norma.

Sendo então o preceito uma categoria autônoma de norma, cumpre agora delimitar o que seria preceito fundamental.

A priori poderia se pensar que o preceito fundamental seria o mesmo que princípio constitucional, contudo esta ligação é errônea e imprecisa, tendo em vista que já se definiu que os preceitos podem ser tanto princípios quanto regras, já que é norma.

Ademais, no texto constitucional a expressão "preceito fundamental" aparece apenas no $\S 1^{\circ}$ do art. 102, já os princípios estão presentes em diversas passagens constitucionais, portanto se o legislador constituinte quisesse que os preceitos fundamentais fossem sinônimos dos princípios constitucionais, não teria empregado isoladamente esta expressão.

Sobre o tema André Ramos Tavares assim afirma:

O fundamental, portanto, apresenta a conotação daquilo sem o que não há como se identificar uma Constituição. São preceitos fundamentais aqueles que conformam a essência de um conjunto normativo-constitucional. ${ }^{9}$

Assim podemos afirmar que os preceitos fundamentais poderão ser princípios e regras constitucionais, desde que eles sejam considerados essenciais à ordem jurídica constitucional. Então nem todos os princípios constitucionais serão preceitos fundamentais e algumas regras essências poderão ser consideradas preceitos fundamentais.

Tarefa difícil é, portanto, estabelecer quais são os princípios e regras constitucionais que se constituirão preceitos fundamentais.

\footnotetext{
${ }^{8}$ TAVARES. Tratado da argüição de preceito fundamental. 2001, p. 117.

${ }^{9}$ TAVARES. Tratado da argüição de preceito fundamental. 2001, p. 124.

(C) 2008. Departamento de Direito da UFSM. Todos os direitos reservados.
} 
A doutrina não chegou a um consenso sobre o que seriam efetivamente os preceitos fundamentais, sendo que poucos autores se arriscaram a enunciar quais seriam os referidos preceitos.

Nelson Nery Jr. e Rosa Maria Nery asseveram que:

São fundamentais, entre outros, os preceitos constitucionais relativos: ao estado democrático de direito (CF $1 .^{\circ}$ caput); b) à soberania nacional (CF $1 .^{\circ}$ I); c) à cidadania (CF $1 .^{\circ}$ II); d) à dignidade da pessoa humana (CF 1. ${ }^{\circ}$ III); e) aos valores sociais do trabalho e da livre iniciativa $\left.\left(C F 1^{\circ} \mathrm{IV}\right) ; f\right)$ ao pluralismo político $\left.\left(C F 1 .^{\circ} \mathrm{V}\right) ; \mathrm{g}\right)$ aos direitos e garantias fundamentais (CF $\left.5^{\circ}\right)$; h) aos direitos sociais (CF $6 .^{\circ}$ a $\left.9 .^{\circ}\right)$; i) à forma federativa do estado brasileiro; j) à separação e independência dos poderes; l) ao voto universal, secreto, direto e periódico. ${ }^{10}$

A Lei n. 9.882/99 também não se enveredou na tarefa de definir o que seriam os preceitos fundamentais e se omitiu com propriedade, posto que não parece tarefa do legislador ordinário estabelecer formas de violação da Constituição Federal, somente ela teria este condão.

Dentro desta linha doutrinária, Zeno Veloso nos ensina que:

Não nos parecia que o legislador ordinário pudesse indicar os preceitos fundamentais decorrentes da Constituição, cujo descumprimento possibilitaria a argüição. Significaria dar prerrogativa ao Congresso Nacional de eleger, dentro dos princípios, quais os que são fundamentais, vale dizer, essenciais, preponderantes, superiores. Ora, isto é atribuição do constituinte originário, ou do Supremo Tribunal Federal, guardião principal e intérprete máximo do Texto Magno. Além do mais, não poderia o legislador apresentar um elenco definitivo, um painel pronto e acabado dos preceitos fundamentais, pois a Constituição, apesar do ideal de estabilidade, é um documento históricocultural do povo. Embora lentas, as transformações são inevitáveis, ditando, como disse Krüger, uma mudança de natureza das normas constitucionais. $O$ que hoje se pode considerar preceito fundamental, dada a dinamicidade do ordenamento jurídico, pode ter a sua densidade normativa diminuída no decorrer do tempo. (...) Estes são princípios reitores, regras nucleares, linhas mestras ou vigas-mestras da organização política e social brasileira, sem olvidar que há preceitos fundamentais que deles decorrem, havendo necessidade, para descobri-los de ser feita uma inferência, um desenvolvimento por parte do intérprete. ${ }^{11}$

\footnotetext{
${ }^{10}$ NERY JR.; NERY. Código de processo civil comentado e legislação processual civil extravagante em vigor. 2002, p. 1478.

${ }^{11}$ VELOSO. Controle jurisdicional de constitucionalidade. 2003, p. 295 e 296.

(C) 2008. Departamento de Direito da UFSM. Todos os direitos reservados.
} 
E como a própria Carta Política não os definiu, quem poderia exercer a função de fixar quais são os preceitos fundamentais?

André Ramos Tavares afirma que a definição dos preceitos fundamentais, deve ser feita pelo Tribunal Constitucional - no caso brasileiro o Supremo Tribunal Federal já que é ele o guardião da Constituição:

(...) é preciso insistir que o correto dimensionamento de cada um dos preceitos fundamentais dar-se-á por obra do Tribunal Constitucional, identificando, em cada caso a ele submetido, a ocorrência ou não de violação a determinado preceito fundamental, com o que acabará, inexoravelmente, apontando e construindo, pouco a pouco, o conteúdo dos preceitos fundamentais. ${ }^{12}$

O próprio STF reconhece esta legitimidade, como se pode verificar na ementa do julgamento da Questão de Ordem na ADPF n. 1:

Compete ao Supremo Tribunal Federal o juízo acerca do que se há de compreender, no sistema constitucional brasileiro, como preceito fundamental. (...) (ADPF 1-QO, Rel. Min. Néri da Silveira, julgamento em 3-2-00, DJ de 7$11-03)$

Ocorre que, a jurisprudência do STF ainda não está plenamente pacificada sobre a construção do significado normativo do que seja preceito fundamental. Porém, no julgamento da ADPF n. 33, o relator Ministro Gilmar Ferreira Mendes, em uma decisão monocrática (que foi chancelada pelo Pretório Excelso) apresentou as idéias que conduzem à compreensão do que a expressão preceito fundamental abrange, senão vejamos:

Parâmetro de controle - É muito difícil indicar, a priori, os preceitos fundamentais da Constituição passíveis de lesão tão grave que justifique o processo e o julgamento da argüição de descumprimento. Não há dúvida de que alguns desses preceitos estão enunciados, de forma explícita, no texto constitucional. Assim, ninguém poderá negar a qualidade de preceitos fundamentais da ordem constitucional aos direitos e garantias individuais (art. $5^{\circ}$, dentre outros). Da mesma forma, não se poderá deixar de atribuir essa qualificação aos demais princípios protegidos pela cláusula pétrea do art. 60, $\$ 4^{o}$, da Constituição, quais sejam, a forma federativa de Estado, a separação de Poderes e o voto direto, secreto, universal e periódico. Por outro lado, a própria Constituição explicita os chamados 'princípios sensíveis', cuja violação pode dar ensejo à decretação de intervenção federal nos Estados-

12 TAVARES. Tratado da argüição de preceito fundamental. 2001, p. 154.

(C) 2008. Departamento de Direito da UFSM. Todos os direitos reservados. 
Membros (art. 34, VII). É fácil ver que a amplitude conferida às cláusulas pétreas e a idéia de unidade da Constituição (Einheit der Verfassung) acabam por colocar parte significativa da Constituição sob a proteção dessas garantias. (...) O efetivo conteúdo das 'garantias de eternidade' somente será obtido mediante esforço hermenêutico. Apenas essa atividade poderá revelar os princípios constitucionais que, ainda que não contemplados expressamente nas cláusulas pétreas, guardam estreita vinculação com os princípios por elas protegidos e estão, por isso, cobertos pela garantia de imutabilidade que delas dimana. Os princípios merecedores de proteção, tal como enunciados normalmente nas chamadas 'cláusulas pétreas', parecem despidos de conteúdo específico. Essa orientação, consagrada por esta Corte para os chamados 'princípios sensiveis', há de se aplicar à concretização das cláusulas pétreas e, também, dos chamados 'preceitos fundamentais'. (...) É o estudo da ordem constitucional no seu contexto normativo e nas suas relações de interdependência que permite identificar as disposições essenciais para a preservação dos princípios basilares dos preceitos fundamentais em um determinado sistema. (...) Destarte, um juízo mais ou menos seguro sobre a lesão de preceito fundamental consistente nos princípios da divisão de Poderes, da forma federativa do Estado ou dos direitos e garantias individuais exige, preliminarmente, a identificação do conteúdo dessas categorias na ordem constitucional e, especialmente, das suas relações de interdependência. Nessa linha de entendimento, a lesão a preceito fundamental não se configurará apenas quando se verificar possível afronta a um princípio fundamental, tal como assente na ordem constitucional, mas também a disposições que confiram densidade normativa ou significado específico a esse princípio. Tendo em vista as interconexões e interdependências dos princípios e regras, talvez não seja recomendável proceder-se a uma distinção entre essas duas categorias, fixando-se um conceito extensivo de preceito fundamental, abrangente das normas básicas contidas no texto constitucional. (ADPF 33-MC, voto do Min. Gilmar Mendes, julgamento em 29-10-03, DJ de 6-8-04)

Vejamos também a decisão da $\operatorname{ADPF}$ n. 45, que reconhece como preceito fundamental os direitos sociais:

ARGÜIÇÃO DE DESCUMPRIMENTO DE PRECEITO FUNDAMENTAL. A QUESTÃO DA LEGITIMIDADE CONSTITUCIONAL DO CONTROLE E DA INTERVENÇÃO DO PODER JUDICIÁRIO EM TEMA DE IMPLEMENTAÇÃO DE POLÍTICAS PÚBLICAS, QUANDO CONFIGURADA HIPÓTESE DE ABUSIVIDADE GOVERNAMENTAL. DIMENSÃO POLÍTICA DA JURISDIÇÃO CONSTITUCIONAL ATRIBUÍDA AO SUPREMO TRIBUNAL FEDERAL. INOPONIBILIDADE DO ARBÍTRIO ESTATAL À EFETIVAÇÃO DOS DIREITOS SOCIAIS, ECONÔMICOS E CULTURAIS. CARÁTER RELATIVO DA LIBERDADE DE CONFORMAÇÃO DO LEGISLADOR. CONSIDERAÇÕES EM TORNO DA CLÁUSULA DA "RESERVA DO POSSÍVEL". NECESSIDADE DE PRESERVAÇÃO, EM FAVOR DOS INDIVÍDUOS, DA INTEGRIDADE E DA INTANGIBILIDADE DO NÚCLEO CONSUBSTANCIADOR DO "MÍNIMO EXISTENCIAL". VIABILIDADE INSTRUMENTAL DA ARGÜIÇÃO DE DESCUMPRIMENTO

(C) 2008. Departamento de Direito da UFSM. Todos os direitos reservados. 
NO PROCESSO DE CONCRETIZAÇÃO DAS LIBERDADES POSITIVAS (DIREITOS CONSTITUCIONAIS DE SEGUNDA GERAÇÃO). (STF - Pleno MC ADPF n. 45- Rel. Min. Celso de Melo, julgamento 29/04/04, DJ de 04-0504)

\section{O PRECEITO FUNDAMENTAL DECORRENTE DA CONSTITUIÇÃO}

Após estabelecer o que são preceitos fundamentais é preciso levar em consideração que o texto constitucional menciona "preceito fundamental decorrente desta constituição"

Para alguns autores esta expressão não foi muito bem empregada, pois gera uma certa ambigüidade, sendo o mais preciso se estivesse grafado: preceito fundamental da Constituição.

O aclamado doutrinador José Afonso da Silva, sobre o tema, prescreve que:

$O \S .1^{o}$ do art. 102 contém uma disposição não muito bem redigida, tal como deve dizer 'preceito fundamental decorrente desta Constituição' quando deveria apenas falar em 'preceito fundamental da Constituição', mas isso não infirma nem prejudica a relevância da norma $(. . .)^{13}$

Desta forma ao inserir o termo "decorrente", poderia dar ensejo à conclusão de que seria possível a localização do preceito externamente à Constituição.

Porém seguindo-se a posição doutrinária de André Ramos Tavares, o vocábulo "decorrente" é designativo da existência de preceitos fundamentais tanto expressos quanto implícitos, mas sempre dentro da Constituição, nunca fora.

Portanto, a argüição de descumprimento de preceito fundamental somente pode ocorrer quando houver violação de preceito fundamental da Constituição, seja ele expresso ou implícito.

\section{CONSIDERAÇÕES FINAIS}

A definição do significado da expressão preceito fundamental como pudemos verificar é tormentosa na doutrina, mas isso se dá porque alguns doutrinadores buscam

\footnotetext{
${ }^{13}$ SILVA. Curso de direito constitucional positivo. 2001, p. 561.

(C) 2008. Departamento de Direito da UFSM. Todos os direitos reservados.
} 
fixar conceitos para todos os institutos jurídicos, porém nem tudo pode ser conceituado com precisão. O preceito fundamental é um exemplo claro disto.

Então melhor que fixar um conceito ou estabelecer o que é ou não é preceito fundamental, é concluir que como a argüição de preceito fundamental surge da violação de um preceito fundamental, o órgão mais competente e melhor preparado para definir o alcance e o significado da expressão preceito fundamental é sem dúvida o guardião da constituição, no âmbito brasileiro o Supremo Tribunal Federal.

Assim, diante destas ponderações podemos afirmar que, a construção do conceito de preceito fundamental é gradativa deve e ser perspectivada à luz do princípio da razoabilidade tendo em vista que se trata de uma expressão que contém alto grau de indeterminabilidade.

\section{REFERÊNCIAS BIBLIOGRÁFICAS}

ARAUJO, Alberto David; NUNES JUNIOR, Vidal Serrano. Curso de direito constitucional. São Paulo: Saraiva, 2006.

CANOTILHO, J. J. Gomes. Direito constitucional e teoria da constituição, Coimbra: Almedina. 2000.

DIMOULIS, Dimitri. Dicionário brasileiro de direito constitucional. São Paulo: Saraiva, 2007.

LENZA, Pedro. Direito constitucional esquematizado. São Paulo: Método, 2007.

MORAES, Alexandre de. Constituição do Brasil interpretada e legislação constitucional. São Paulo: Atlas, 2002.

Direito constitucional. São Paulo: Atlas, 2006.

NERY JR., Nelson; NERY, Rosa M. A.. Código de processo civil comentado e legislação processual civil extravagante em vigor. São Paulo: Revista dos Tribunais, 2002.

SILVA, José Afonso. Curso de direito constitucional positivo.São Paulo: Malheiros, 2001.

TAVARES, André Ramos. Tratado da argüição de preceito fundamental. São Paulo: Saraiva, 2001. 
VELOSO, Zeno. Controle jurisdicional de constitucionalidade. Belo Horizonte: Del Rey, 2003. 